\title{
QUALIDADE DE VIDA NO SERVIÇO PÚBLICO: UMA AVALIAÇÃO EM UMA INSTITUIÇÃO DE ENSINO SUPERIOR ${ }^{1}$
}

\author{
Leander Luiz Klein ${ }^{2}$ \\ Ricardo Brião Lemos ${ }^{3}$ \\ Breno Augusto Diniz Pereira ${ }^{4}$ \\ Gabriela Beltrame ${ }^{5}$
}

http://dx.doi.org/10.1590/1413-2311.158.59511

\begin{abstract}
RESUMO
Na área da gestão de pessoas, o estudo da Qualidade de Vida no Trabalho (QVT), por envolver vários aspectos, tem se tornado um fator estratégico para melhorar a produtividade interna nas organizações. O presente estudo tem como objetivo analisar os fatores direcionadores da QVT, com base na percepção de servidores de uma organização pública. A base teórica se constituiu de conceitos e modelos sobre a QVT e do modelo de Ferreira (2011), que foi tomado como base para o desenvolvimento da pesquisa empírica. O método deste trabalho é uma pesquisa survey realizada por meio $=$ de um questionário. A população são os servidores docentes e técnicos administrativos de uma universidade federal de ensino superior do interior do estado do Rio Grande do Sul. Conseguiu-se 474 questionários respondidos, o que corresponde a um erro amostral de 4,59\%. Para a mensuração da opinião dos servidores utilizou-se uma escala do tipo Likert de cinco pontos. A análise de dados foi realizada por meio de estatística descritiva e estatística multivariada. Como principais resultados pode-se destacar o alcance de 9 fatores obtidos através da análise fatorial exploratória. Para investigar a influência dos fatores encontrados sobre a QVT, realizou-se uma regressão linear múltipla e verificou-se que os fatores Satisfação no Trabalho, Espaço Físico, Oportunidade de Crescimento Profissional e Relacionamento com os Colegas explicam 54,6\% do modelo do estudo. Com a discussão feita sobre os resultados obtidos, conclui-se que o impacto desses fatores não se limita somente a uma melhora na qualidade de vida dos trabalhadores, mas também na produtividade, no comprometimento no trabalho, na saúde do trabalhador e na redução do absenteísmo.
\end{abstract}

Palavras chave: Qualidade de Vida. Trabalho. Instituição de Ensino Superior.

\footnotetext{
${ }^{1}$ Recebido em 22/10/2015; aprovado em 02/08/2017.

${ }^{2}$ Universidade Federal de Santa Maria - kleander88@gmail.com.

${ }^{3}$ Universidade Federal do Pampa - rbriao@ hotmail.com.

${ }^{4}$ Universidade Federal de Santa Maria - brenodpereira@gmail.com.

${ }^{5}$ E-mail: gabibeltrame@hotmail.com.
} 


\title{
QUALITY OF LIFE IN PUBLIC SERVICE: AN EVALUATION IN AN INSTITUTION OF HIGHER EDUCATION
}

\begin{abstract}
In the area of human resources management, the study of Quality of Work Life (QWL), which involves many aspects, has become an important strategic factor for improving the internal productivity of organizations. This study aims to analyze factors that drive to QWL, based on the perception of workers of a public organization. The theoretical basis of the article is constituted by concepts and models of QWL and the presentation of the Ferreira (2011) model, which was taken as a basis for the development of the empirical research. The method is a survey conducted through the use of a questionnaire. The study population are administrative workers and teachers from a federal university of higher education in the state of Rio Grande do Sul. 474 responses were obtained, which correspond to a sampling error of $4,59 \%$. A Likert scale of five points was used to measure the opinion of the servers. Data analysis was performed using descriptive statistics and multivariate statistics. Between the main results that can be emphasized are the 9 factors obtained from exploratory factor analysis. To investigate the influence of these factors on the QWL, it was performed a multiple linear regression, and it was found that the factors Job satisfaction, Physical Space, Professional Growth Opportunity and Relationship with Colleagues explain $54.6 \%$ of the template of this work. With the discussion made about the results obtained, the conclusion is that the impact of these factors is not only limited to an improvement in the quality of life of workers, but also affects their productivity, commitment at work, occupational health and reduces absenteeism.
\end{abstract}

Key Words: Quality of Life. Work. Institution of Higher Education.

\section{CALIDAD DE VIDA EN EL SERVICIO PÚBLICO: UNA EVALUACIÓN EN UNA INSTITUCIÓN DE EDUCACIÓN SUPERIOR}

\begin{abstract}
RESUMEN
En el área de gestión de personal, el estudio de la Calidad de Vida en el Trabajo (CVT), que involucra muchos aspectos, se ha convertido en un importante factor estratégico para la mejora de la productividad interna en las organizaciones. Este estudio tiene como objetivo analizar los factores conductores de CVT, en base a la percepción de los trabajadores de una organización pública. La base teórica del artículo está constituida por conceptos y modelos en CVT y por la presentación del modelo de Ferreira (2011), que fue tomado como base para el desarrollo de la investigación empírica. El método d es una encuesta realizada por medio de un cuestionario. La población de estudio son trabajadores técnicos administrativos y profesores de una universidad federal de educación superior en el estado de Rio Grande do Sul. Se logró 474 respuestas, lo que corresponde a un error de muestreo de 4,59\%. Para medir la opinión de los trabajadores fue utilizada una escala Likert de cinco puntos. Se realizó el análisis de datos mediante estadística descriptiva y estadística multivariante. Entre los principales resultados que se pueden destacar están los 9 factores obtenidos por medio del análisis factorial exploratorio. Para investigar la influencia de esos factores en la CVT, fue

REAd | Porto Alegre - Vol. 23 - No Especial - Dezembro 2017 - p. 317-344
\end{abstract}


realizada una regresión linear múltiple y encontrado que los factores Satisfacción Laboral, Espacio Físico, Oportunidad de Crecimiento Profesional y la Relación con los Colegas explican el 54,6\% de la plantilla do trabajo. Con la discusión hecha de los resultados obtenidos, la conclusión es que el impacto de estos factores no se limita sólo a una mejora en la calidad de vida de los trabajadores, sino también de su productividad, su compromiso en el trabajo, la salud laboral y la reducción de absentismo.

Palabras Clave: Calidad de Vida. Trabajo. Institución de Educación Superior.

\section{INTRODUÇÃO}

Não é incomum, na atualidade, ver pessoas se engajando em ações para contestação de melhorias no trabalho ou em greves. Estes trabalhadores talvez sintam que foram tratados de forma injusta ou são injustamente remunerados em seu local de trabalho (CHINOMONA; CHENG, 2013). Vários outros motivos podem estar envolvidos nesses movimentos, mas o fato é que, conforme enfatizam Siqueira e Mendes (2009), a forma de trabalhar requerida e as relações interpessoais já não são as mesmas de outras épocas, o que direciona a revisão de práticas organizacionais de gestão. Nesse sentido, na área da gestão de pessoas, o estudo da qualidade de vida no trabalho (QVT), por envolver vários aspectos, tem se tornado um fator estratégico para melhorar a produtividade interna das organizações.

No contexto atual das organizações, para que elas possam se manter estáveis e bem vistas no mercado, não basta à instituição garantir a qualidade dos aspectos técnicos do processo produtivo, é preciso investir nas pessoas envolvidas. Para Maximiliano (2007), este pensamento caracteriza o enfoque biopsicossocial que propõe a visão holística da organização que integra o ser humano. Especificamente em relação às organizações públicas, mudanças ocorridas no contexto do trabalho, como a cobrança por transparência e melhor alocação dos recursos, produzem impactos e trazem novos desafios relativos ao papel e finalidades desses órgãos.

Esses processos se desenvolvem em um contexto de consolidação de direitos e valores democráticos, com novos atores sociais que forjam uma nova cidadania.Nele, processos de modernização poderão acarretar resultados negativos para o quadro de servidores, como o aumento de índices de absenteísmo, acidentes, doenças do trabalho e licenças-saúde (FERREIRA, 2011). No entanto, para Fernandes (1996), a preocupação com a qualidade de vida não deve deixar em segundo plano a eficiência do serviço público. A obtenção de melhores resultados é também necessária e deve ser conciliada com a QVT.

REAd | Porto Alegre - Vol. 23 - No Especial - Dezembro 2017 - p. 317-344 
Diante dessa perspectiva, tanto pesquisadores quanto experts práticos tem ponderado e se questionado sobre o que deve ser feito para motivar pessoas e torná-las comprometidas em suas atividades no trabalho. No entendimento de Sant'Anna, Kilimnik e Moraes (2011), há um ponto em comum entre os estudiosos do tema que é a aplicabilidade de pressupostos humanistas visando modificar aspectos no e do trabalho para propiciar melhorias em relação à satisfação dos empregados e, com isso, obter aumento na produtividade.

No entanto, Ferreira et al. (2009) argumentam que há ainda uma necessidade dos gestores em repensar as práticas organizacionais, buscando responder eficientemente às exigências da atual conjuntura e pressupondo uma reestruturação, principalmente em termos de gestão de pessoas, na qual o bem-estar dos servidores públicos, a satisfação do usuáriocidadão e a eficácia dos serviços prestados pelos órgãos governamentais constituam desafios inerentes às práticas de gestão. Diante disso, o presente estudo tem como objetivo analisar os fatores direcionadores da QVT com base na percepção de servidores de uma organização pública.

Especificamente na área pública, pode-se mencionar estudos recentes que envolvem a QVT e/ou seus elementos, como os de Vasconcelos et al. (2012), Oliveira et al. (2012), Traldi e Demo (2012), Claro e Profeta (2015), Cavedon (2014), Silva e Ferreira (2013), entre outros. Isso demostra a importância de envolver esse tema em questões cotidianas do trabalho. Além disso, sob o ponto de vista acadêmico, acredita-se ainda haver espaço e necessidade para novas interlocuções empíricas para consolidar o entendimento dos elementos influenciadores da QVT. A lacuna que se quer preencher diz respeito à perspectiva de consolidação dos vários fatores relacionados à QVT. Para o campo prático, as teorizações que serviram de fundamento para a investigação do campo empírico e os resultados deste estudo permitirão o avanço do saber sobre a categoria profissional em estudo e o conhecimento de pontos de discussão de diferentes aspectos da QVT, de modo a contribuir com a melhoria de práticas de gestão e produtividade.

\section{QUALIDADE DE VIDA NO TRABALHO}

Nesta parte do trabalho pretende-se constituir uma base teórica para o esclarecimento sobre a QVT, bem como um alicerce para o desenvolvimento do artigo. São apresentados, primeiramente, conceitos sobre o objeto de pesquisa de estudo. Após, apresentam-se os 
principais modelos teóricos de estudo sobre o tema e alguns pontos convergentes e divergentes entre eles.

\subsection{CONCEITOS E ÊNFASES DA QUALIDADE DE VIDA NO TRABALHO}

O termo Qualidade de Vida no Trabalho abrange muitos significados que refletem conhecimentos, experiências e valores de indivíduos e da coletividade. A respeito do termo, verifica-se uma evolução e aprimoramento de sua definição com a inserção de novas variáveis ao longo do tempo. Muitos autores se dedicaram ao estudo do tema e possibilitaram o melhor entendimento e completude sobre os elementos e variáveis que envolvem a QVT.

Um dos primeiros pesquisadores a se dedicar ao estudo desse assunto foi Walton (1973). O referido autor entende a QVT como algo que vai além dos objetivos da legislação trabalhista, que surgiu no começo do século $\mathrm{XX}$ com a regulamentação do trabalho de menores, da jornada de trabalho e descanso semanal e das indenizações por acidentes de trabalho. Para o autor, a QVT se destaca como forma de resgatar os valores humanísticos e ambientais que foram negligenciados em favor do avanço tecnológico, da produtividade e do crescimento econômico.

Westley (1979) compreende a QVT como esforços voltados para a humanização do trabalho, buscando solucionar problemas gerados pela própria natureza das organizações produtivas. Para Nadler e Lawler (1983), isso envolve a maneira de pensar a respeito das pessoas, participação na resolução de problemas, enriquecimento e melhoria no ambiente de trabalho. No entendimento de Huse e Cummings (1985), ao se falar em QVT deve-se ter a preocupação com o bem-estar do trabalhador, com a eficácia organizacional e a participação dos trabalhadores nas decisões e problemas do trabalho.

Neste trabalho, QVT é definida como o grau em que os trabalhadores de uma organização são capazes de satisfazer as suas importantes necessidades pessoais, por meio de suas experiências no local de trabalho (IGBARIA; PARASURAMAN; BADAWY, 1994). A QVT é representada por condições e ambientes favoráveis, em um local de trabalho, que apoiam e promovem a satisfação no trabalho do indivíduo, estimulando-o com melhores sistemas de recompensa, segurança no trabalho e oportunidades de crescimento (SIRGY et al., 2001).

Verifica-se que muitos aspectos e variáveis estão envolvidos nesse tema, bem como REAd | Porto Alegre - Vol. 23 - No Especial - Dezembro 2017 - p. 317-344 
diferentes ênfases. Pode-se observar no estudo da QVT o envolvimento da humanização e responsabilidade social (WALTON, 1973), crescimento pessoal (LIPPITT, 1978), auto realização e melhora da produtividade e eficiência (GUEST, 1979), valorização dos cargos (HUSE; CUMMINGS, 1985; WERTHER; DAVIS, 1983), bem-estar do trabalhador (FERNANDES, 1996) etc. Outros pesquisadores têm focado em resultados relacionados com o trabalho ou respostas comportamentais dos funcionários, como a identificação organizacional, satisfação no trabalho, envolvimento com o trabalho, esforço de trabalho, desempenho no trabalho, intenção de parar e alienação pessoal (EFRATY; SIRGY, 1990; EFRATY; SIRGY; CLAIBORNE, 1991; KOYS, 2001; BISWAS, 2010). Isso revela o quão abrangente e complexo se torna o estudo da QVT.

\subsection{MODELOS DE QVT E SEUS ELEMENTOS}

Da mesma forma que são abordados vários conceitos de QVT, diferentes modelos foram propostos para as pesquisas nesse assunto. De acordo com El-Aouar e Souza (2003), o movimento de QVT surge e se desenvolve sistematizado sob a forma de modelos destinados à redução de conflitos entre capital e trabalho, e visa conciliar os diferentes interesses de trabalhadores e empregadores. Diferentes variáveis e perspectivas de estudo da QVT são envolvidas nesses modelos. Como forma de sistematizar e sintetizar esses modelos, além de constituir parte da base teórica desse artigo, elaborou-se o Quadro 1, no qual descrevem-se alguns dos principais modelos referentes a QVT.

Analisando-se o Quadro 1, pode-se observar uma relativa alternância entre os fatores críticos apontados pelos modelos clássicos de QVT. De forma geral, modelos desenvolvidos por estudiosos como Walton (1975), Westley (1979), Nadler e Lawler (1983), Werther e Davis (1983), Huse e Cummings (1985) e Hackman e Oldham (1975) indicam que a QVT perpassa alguns pontos específicos, tais como: sistema de recompensas diretas e indiretas; condições do ambiente de trabalho; concepção do trabalho e das tarefas em si; autonomia e participação conferidas ao indivíduo no trabalho; imagem social que a organização desperta sobre seus funcionários; equilíbrio entre o tempo de trabalho, da família e do lazer, que influenciam positivamente a satisfação no trabalho e, consequentemente, o desempenho dos trabalhadores.

REAd | Porto Alegre - Vol. 23 - No Especial - Dezembro 2017 - p. 317-344 
Quadro 1 - Modelos de QVT

\begin{tabular}{|c|c|c|}
\hline MODELO & DESCRIÇÃO & Dimensões Consideradas \\
\hline $\begin{array}{l}\text { Modelo de } \\
\text { Walton } \\
(1973)\end{array}$ & $\begin{array}{l}\text { O alto grau de envolvimento } \\
\text { que resulta do incentivo à } \\
\text { autonomia, à responsabilidade } \\
\text { pela tarefa como um todo e ao } \\
\text { espírito de equipe, podem } \\
\text { eventualmente atuar contra o } \\
\text { equilíbrio entre a vida } \\
\text { profissional a pessoal, sem a } \\
\text { necessidade de baixar o nível } \\
\text { de QVT em uma categoria. O } \\
\text { autor buscou identificar as } \\
\text { dimensões e variáveis que } \\
\text { afetam de maneira mais } \\
\text { significativa o trabalhador } \\
\text { exposto à situação de } \\
\text { trabalho. }\end{array}$ & $\begin{array}{l}\checkmark \text { Compensação justa e adequada: remuneração recebida } \\
\text { pelo trabalho realizado e avaliação da equidade dessa } \\
\text { remuneração; } \\
\checkmark \text { Condições de trabalho seguras e saudáveis: condições } \\
\text { existentes no local de trabalho e aspectos que podem influenciar } \\
\text { na saúde do trabalhador; } \\
\checkmark \text { Uso e desenvolvimento de capacidades pessoais: } \\
\text { mensuração das oportunidades que o empregado tem de aplicar } \\
\text { no seu dia a dia, habilidades e conhecimentos, além de } \\
\text { feedbacks quanto ao seu desempenho; } \\
\checkmark \text { Oportunidades de crescimento e segurança: } \\
\text { desenvolvimento pessoal e estabilidade no emprego; } \\
\checkmark \text { Integração social na organização: descaracterização de } \\
\text { grandes desníveis na escala hierárquica, reforço ao espírito de } \\
\text { colaboração e sinceridade nas relações interpessoais; } \\
\checkmark \text { Constitucionalismo: direitos dos empregados cumpridos na } \\
\text { instituição; } \\
\checkmark \text { Trabalho e espaço total na vida: equilíbrio entre a vida } \\
\text { social e no trabalho do empregado; } \\
\checkmark \text { Relevância social do trabalho: percepção do empregado } \\
\text { em relação à responsabilidade social da instituição na } \\
\text { comunidade, à qualidade de prestação dos serviços e ao } \\
\text { atendimento de seus empregados. }\end{array}$ \\
\hline $\begin{array}{l}\text { Modelo de } \\
\text { Westley } \\
\text { (1979) }\end{array}$ & $\begin{array}{l}\text { Westley defende a } \\
\text { necessidade de humanização } \\
\text { nas atividades laborais para } \\
\text { que se obtenha a QVT } \\
\text { desejada. Tanto aspectos } \\
\text { internos quanto externos à } \\
\text { organização devem e podem } \\
\text { afetar a qualidade de vida dos } \\
\text { trabalhadores e têm origem na } \\
\text { organização e transformação } \\
\text { do trabalho na sociedade } \\
\text { industrial. }\end{array}$ & $\begin{array}{l}\checkmark \text { Econômica: Avaliação justa entre o trabalho prestado e a } \\
\text { contraprestação financeira; } \\
\checkmark \text { Política: se refere à sensação de estabilidade no emprego, } \\
\text { autonomia para atuação sindical, feedback extrínseco, liberdade } \\
\text { para manifestar-se, reconhecimento e valorização do cargo } \\
\text { exercido e acessibilidade e bom relacionamento com a chefia; } \\
\checkmark \text { Psicológica: aborda fatores motivacionais como feedback } \\
\text { intrínseco, realização pessoal, nível de desafio, } \\
\text { desenvolvimento pessoal e profissional, criatividade, variedade } \\
\text { de tarefas e reconhecimento das habilidades individuais; } \\
\checkmark \text { Sociológica: defende normas regulamentadoras nas relações } \\
\text { no trabalho, destacando a conveniência de possibilitar-se a } \\
\text { participação ativa do trabalhador no processo de trabalho e na } \\
\text { tomada de decisões, com o desenvolvimento das relações } \\
\text { interpessoais e a promoção de uma maior conscientização das } \\
\text { suas responsabilidades individuais dentro da equipe. }\end{array}$ \\
\hline $\begin{array}{l}\text { Modelo de } \\
\text { Werther e } \\
\text { Davis } \\
\text { (1983) }\end{array}$ & $\begin{array}{l}\text { A QVT se estabelece em } \\
\text { função do cargo exercido pelo } \\
\text { indivíduo, por ser a ligação } \\
\text { entre o trabalhador e o } \\
\text { empregador. Pretendia a } \\
\text { concretização de um trabalho } \\
\text { com maiores índices de } \\
\text { produtividade e com elevado } \\
\text { grau de satisfação de todos os } \\
\text { colaboradores. }\end{array}$ & $\begin{array}{l}\checkmark \text { Organizacional: busca a identificação de todas as tarefas } \\
\text { concernentes ao cargo para que seja estabelecido o estudo da } \\
\text { metodologia adequada ao seu desempenho, com a } \\
\text { implementação de práticas e racionalização de rotinas; } \\
\checkmark \text { Ambiental: envolve circunstâncias sociais, culturais, } \\
\text { históricas, competitivas, econômicas, governamentais e } \\
\text { tecnológicas; } \\
\checkmark \text { Comportamental: avaliação das necessidades dos } \\
\text { trabalhadores, tanto no que diz respeito aos recursos humanos } \\
\text { quanto aos critérios motivacionais e grau de satisfação. }\end{array}$ \\
\hline
\end{tabular}


Quadro 1 - Modelos de QVT

\begin{tabular}{|c|c|c|}
\hline MODELO & DESCRIÇÃ̃O & Dimensões Consideradas \\
\hline $\begin{array}{l}\text { Modelo de } \\
\text { Huse e } \\
\text { Cummings } \\
(1985)\end{array}$ & $\begin{array}{l}\text { A QVT é uma forma de } \\
\text { pensar que relaciona pessoas, } \\
\text { trabalho e organização, tendo } \\
\text { como principais aspectos a } \\
\text { preocupação com o } \\
\text { trabalhador e com a eficácia } \\
\text { organizacional e sua } \\
\text { participação nas decisões e } \\
\text { soluções de problemas. } \\
\text { Defendem que o cargo deve } \\
\text { atender as necessidades } \\
\text { tecnológicas do trabalhador; }\end{array}$ & $\begin{array}{l}\checkmark \text { Participação do trabalhador: envolvimento do empregado } \\
\text { no processo de tomada de decisões e resolução de problemas } \\
\text { por meio da criação de grupos de trabalho cooperativos e da } \\
\text { inclusão dos operários de linha na análise e solução de } \\
\text { problemas de produção; } \\
\checkmark \text { Projeto de cargos: atender as necessidades tecnológicas do } \\
\text { trabalhador, incluindo o enriquecimento do trabalho, o feedback } \\
\text { e os grupos de trabalho autorregulados; } \\
\checkmark \text { Inovação no sistema de recompensas: plano de cargos e } \\
\text { salários da organização, visando minimizar as diferenças } \\
\text { salariais entre os níveis e de status entre os trabalhadores; } \\
\checkmark \text { Melhoria no ambiente de trabalho: com mudanças físicas } \\
\text { nas condições de trabalho, por meio de uma flexibilização de } \\
\text { horários; instituição de grupos semi autônomos e modificações } \\
\text { no local ou nos equipamentos de trabalho. }\end{array}$ \\
\hline $\begin{array}{l}\text { Modelo de } \\
\text { Hackmann } \\
\text { e Oldhan } \\
(1975)\end{array}$ & $\begin{array}{l}\text { Propõe uma teoria relacionada } \\
\text { às dimensões básicas da } \\
\text { tarefa, que influenciam psico } \\
\text { e logicamente o trabalhador e } \\
\text { sua produtividade dentro da } \\
\text { organização. Sistematizaram } \\
\text { as dimensões ou } \\
\text { características do cargo, } \\
\text { consideradas determi-nantes } \\
\text { da QVT. }\end{array}$ & $\begin{array}{l}\checkmark \quad \text { Variedade de habilidades: grau em que as atividades } \\
\text { profissionais demandam a utilização de diversas habilidades do } \\
\text { profissional; } \\
\checkmark \quad \text { Identidade da tarefa: grau em que a tarefa requer a } \\
\text { execução de um trabalho do início ao fim, e que este seja } \\
\text { identificável; } \\
\checkmark \quad \text { Significado da tarefa: grau que proporciona à tarefa } \\
\text { ao impactar a vida ou trabalho de outras pessoas; } \\
\checkmark \quad \text { Autonomia: grau em que a tarefa fornece aos } \\
\text { indivíduos liberdade para planejar e executar suas atividades; } \\
\checkmark \quad \text { Feedback: retorno que o indivíduo recebe pelo seu } \\
\text { desempenho relacionado com o seu trabalho. }\end{array}$ \\
\hline $\begin{array}{l}\text { Modelo de } \\
\text { Nadler e } \\
\text { Lawler } \\
(1983)\end{array}$ & $\begin{array}{l}\text { A QVT consiste na busca de } \\
\text { maior produtividade, } \\
\text { conciliada com a motivação e } \\
\text { a satisfação do indivíduo. }\end{array}$ & $\begin{array}{l}\text { Elencou fatores determinantes para o sucesso de projetos de } \\
\text { QVT: } \\
\checkmark \text { A percepção da necessidade; } \\
\checkmark \text { A estrutura para identificação e solução do problema; } \\
\checkmark \text { O foco do problema que é detectado na organização; } \\
\checkmark \text { As compensações projetadas, tanto para os processos } \\
\text { quanto para os resultados; } \\
\checkmark \text { Os sistemas múltiplos afetados; } \\
\checkmark \text { O amplo envolvimento da organização. }\end{array}$ \\
\hline
\end{tabular}

Fonte: Elaborado pelos autores.

De acordo com Sant'anna e Moraes (1999), há que se ressaltar que os diversos modelos de QVT diferem em função da dinâmica das abordagens, variando conforme os valores culturais predominantes em cada época, os contextos sócio-político-econômicos prevalecentes e as experiências prévias de cada pesquisador. Em virtude disso, pode-se identificar que modelos de diagnóstico de QVT, como o de Walton (1975) e Westley (1979), são mais abrangentes porque compreendem a análise de uma amplitude maior de variáveis. Outros modelos se caracterizam pelo foco em variáveis específicas quanto às suas abordagens, como nos modelos de Nadler e Lawler (1983), Werther e Davis (1983), Huse e Cummings (1985), que se direcionam ao estudo do cargo. Outros, às dimensões básicas da

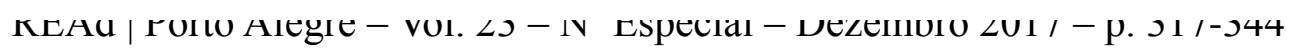


tarefa, como no modelo de Hackman e Oldham (1975).

De qualquer forma, todos os modelos trazem elementos importantes para a discussão da QVT. Esses modelos servem de base para o estudo do tema na atualidade e para a proposição de novos modelos, como o modelo de Ferreira (2011), que foi tomado para a consecução deste trabalho.

O modelo de Ferreira (2011) tem como base a abordagem da Ergonomia da Atividade, desenvolvida por meio de duas versões consecutivas (períodos de 2005-2008 e 2008-2011). A concepção adotada se filia aos argumentos de Amalberti et al. (1991), salientando que os modelos em ergonomia têm quatro funções básicas: reduzir, descrever, explicar e simular. $\mathrm{O}$ modelo se caracteriza por conhecimentos datados que servem como meio de inferência para a validação científica de dados obtidos e tem papel heurístico para explicar o mecanismo e os fatores constitutivos de QVT. Esse modelo descritivo busca, portanto, explicitar os níveis analíticos que o compõe, os fatores e as dimensões que o integram e os métodos correspondentes em cada nível.

No modelo de Ferreira (2011), a QVT é analisada com base em dois níveis analíticos: macro ergonômico e o micro ergonômico. No nível macro, são identificadas representações que os trabalhadores expressam sobre o contexto organizacional onde estão inseridos, sendo que nesse nível o diagnóstico é feito com base na utilização de um Inventário de Avaliação de Qualidade de Vida no Trabalho (IAQVT). As representações que balizam e modulam a presença ou ausência de qualidade de vida estão polarizadas em duas modalidades de representações de natureza afetiva: o bem-estar no trabalho e o mal-estar no trabalho (FERREIRA, 2011).

Já no nível micro, a compreensão de qualidade de vida é analisada com base nos elementos obtidos no nível macro ergonômico. Se, em certa medida, o nível macro analítico produz como resultado uma "fotografia" ampla de como os trabalhadores representam cognitivamente os fatores constitutivos de qualidade de vida, no nível micro busca-se investigar os impactos produzidos por estes fatores e os modos pelos quais os trabalhadores lidam com as exigências que nascem dos contextos de suas atividades laborais (FERREIRA, 2011).

A escolha do modelo de Ferreira (2011) para a realização desse trabalho se deve ao fato da Pró-Reitoria de Gestão de Pessoas da instituição analisada utilizar esse modelo em seus estudos e como referência para a implantação da QVT no ambiente organizacional. Além

REAd | Porto Alegre - Vol. 23 - No Especial - Dezembro 2017 - p. 317-344 
disso, o modelo de Ferreira (2011) adota uma abordagem que tem como base um diagnóstico dentro da organização e por meio da percepção de seus servidores em relação aos fatores intervenientes nas suas qualidades de vida, com um foco na QVT preventiva, na qual as tarefas e o contexto de trabalho e seus componentes devem ser adaptados aos trabalhadores. Dessa forma, esses fatores proporcionariam maior confiabilidade aos resultados encontrados.

\section{MÉTODO}

O método deste trabalho é uma pesquisa do tipo survey realizado por meio da utilização de um questionário fechado. A amostra deste estudo é constituída por servidores docentes e técnicos administrativos de uma universidade federal de ensino superior, distribuídos em 10 campi do interior do estado do Rio Grande do Sul.

A escolha dessa instituição se deve ao fato de que ela possui um Programa de Qualidade de Vida no Trabalho, sob a responsabilidade da Coordenadoria de Acompanhamento Funcional e Saúde da Pró-Reitoria de Gestão de Pessoas (PROGESP). Este fato proporciona maior contribuição aos resultados da pesquisa e, da mesma forma, possibilita que os resultados encontrados auxiliem no melhoramento do programa já implantado.

A instituição possuía no momento da realização da pesquisa um conjunto de servidores composto por 780 docentes e 670 técnicos administrativos. Considerando um erro amostral de 5\%, a amostra necessária para a representatividade da população é de 304 servidores.

A coleta de dados se deu através do envio online dos questionários a todos os servidores dos 10 campi, dos quais conseguiu-se 474 questionários respondidos, o que corresponde a um erro amostral de 4,59\%. O questionário foi composto por questões iniciais de caracterização do perfil dos respondentes e por cinquenta e seis questões que permitiram a avaliação da percepção dos servidores quanto à QVT. A operacionalização das variáveis do questionário foi realizada conforme os indicadores de Ferreira (2011). Os indicadores são os seguintes:

(1) condições de trabalho e suporte organizacional - refere-se a equipamentos de trabalho, matéria prima, espaço físico e suporte organizacional como informações, políticas de remuneração, de capacitação e de benefícios;

(2) organização do trabalho - mede a adequação do tempo, processo e divisão do

REAd | Porto Alegre - Vol. 23 - No Especial - Dezembro 2017 - p. 317-344 
trabalho, bem como a gestão do trabalho e padrões de conduta que se referem à supervisão e fiscalização, habilidades higiene e vestimentas;

(3) relações sócio profissionais de trabalho remete às relações hierárquicas com os pares e com público externo;

(4) reconhecimento e crescimento profissional - avaliação do reconhecimento do trabalho realizado, empenho, dedicação, e do crescimento profissional, uso da criatividade, desenvolvimento de competências, capacitações, incentivos, planos de carreira;

(5) elo trabalho-vida social - percepções sobre prazer e bem-estar no trabalho, valorização do tempo vivenciado na organização, sentimento de utilidade social, importância da instituição empregadora, significado pessoal e profissional, vida social, relação trabalhocasa, relação trabalho-família, relação trabalho-amigos e relação trabalho-lazer.

Para a organização da opinião dos servidores utilizou-se se uma escala do tipo Likert de cinco pontos: (1) discordo totalmente; (2) discordo parcialmente; (3) indiferente; (4) concordo parcialmente; e (5) concordo totalmente. O questionário ainda foi composto por uma questão adicional de uma escala de 0 a 10 para avaliar a nota que os servidores dão à sua satisfação com a QVT.

A análise de dados foi realizada em duas fases: estatística descritiva e estatística multivariada. Utilizaram-se os softwares Microsoft Excel e Statiscal Package for the Social Sciences (SPSS 18.0) para a organização, mensuração e realização dos testes desejados. A primeira etapa da análise de dados é a estatística descritiva das variáveis com a finalidade de caracterizar a amostra. Posteriormente, utilizam-se duas técnicas de análise multivariada de dados: a análise fatorial exploratória e a análise de regressão.

A análise fatorial exploratória é utilizada como técnica para reduzir o número de variáveis iniciais para um conjunto de construtos que facilite a análise dos dados obtidos. De acordo com Hair et al. (2009), a análise fatorial aborda como analisar a estrutura de interrelações ou covariâncias existentes entre as variáveis, definindo uma série de dimensões subjacentes comuns, ou seja, os fatores. Pode-se dizer que a análise fatorial é uma técnica desenvolvida para sintetizar as informações por meio da combinação das variáveis, reduzindo-as obtendo os fatores.

Posteriormente, foi realizada a Análise de Regressão Linear, alocando a variável Satisfação com a QVT como variável dependente e, como variáveis independentes, os fatores obtidos na análise fatorial. De acordo com Hair et al. (2009), a regressão linear é efetuada 
para analisar a relação entre uma única variável dependente e demais variáveis independentes. Assim, a regressão linear é utilizada com a finalidade de identificar fatores influenciadores da QVT na instituição estudada.

\section{RESULTADOS E DISCUSSÕES}

\subsection{PERFIL DA AMOSTRA}

O estudo foi realizado com uma amostra de 474 respondentes entre docentes e técnicos administrativos em educação de uma universidade federal de ensino superior. $\mathrm{O}$ perfil dos indivíduos pode ser verificado na Tabela 1.

Tabela 1 - Perfil dos respondentes

(continua)

\begin{tabular}{|c|c|c|}
\hline VARIÁVEL & ALTERNATIVA & PERCENTUAL \\
\hline \multirow{2}{*}{ Sexo } & Masculino & $50,80 \%$ \\
\hline & Feminino & $49,20 \%$ \\
\hline \multirow{4}{*}{ Faixa Etária } & 18 a 30 anos & $25,90 \%$ \\
\hline & 31 a 40 anos & $44,90 \%$ \\
\hline & 41 a 50 anos & $20,50 \%$ \\
\hline & Acima de 50 anos & $8,60 \%$ \\
\hline \multirow{5}{*}{ Nível de Escolaridade } & Médio & $4,40 \%$ \\
\hline & Graduação & $17,10 \%$ \\
\hline & Especialização & $31,00 \%$ \\
\hline & Mestrado & $18,80 \%$ \\
\hline & Doutorado & $28,70 \%$ \\
\hline \multirow{7}{*}{ Função } & Professor Associado & $1,70 \%$ \\
\hline & Professor Adjunto & $24,30 \%$ \\
\hline & Professor Assistente & $10,30 \%$ \\
\hline & Professor Auxiliar & $0,80 \%$ \\
\hline & Professor Substituto & $1,70 \%$ \\
\hline & TAE ensino médio (D) & $27,80 \%$ \\
\hline & TAE ensino superior (E) & $33,30 \%$ \\
\hline \multirow{5}{*}{ Tempo de serviço na universidade } & até 6 meses & $16,50 \%$ \\
\hline & até 1 ano & $8,00 \%$ \\
\hline & até 3 anos & $19,40 \%$ \\
\hline & até 5 anos & $34,80 \%$ \\
\hline & Acima de 5 anos & $21,30 \%$ \\
\hline
\end{tabular}

REAd | Porto Alegre - Vol. 23 - No Especial - Dezembro 2017 - p. 317-344 
Tabela 1 - Perfil dos respondentes

(continua)

\begin{tabular}{clc}
\hline VARIÁVEL & \multicolumn{1}{c}{ ALTERNATIVA } & PERCENTUAL \\
\hline \multirow{3}{*}{ Tempo total no serviço público } & até 6 meses & $9,30 \%$ \\
\cline { 2 - 3 } & até 1 ano & $4,90 \%$ \\
\cline { 2 - 3 } & até 3 anos & $15,00 \%$ \\
\cline { 2 - 3 } & até 5 anos & $27,40 \%$ \\
\cline { 2 - 3 } & Acima de 5 anos & $43,50 \%$ \\
\hline \multirow{2}{*}{ Ocupa cargo de gestão na universidade } & Sim & $21,90 \%$ \\
\cline { 2 - 3 } & Não & $78,10 \%$ \\
\hline
\end{tabular}

Fonte: Elaborado pelos autores com base no resultado da estatística descritiva.

É possível verificar que a maioria dos respondentes pertence ao sexo masculino (50,80\%), possui entre 31 a 40 anos de idade (44,90\%), destacando-se em nível de escolaridade os respondentes com especialização $31 \%$ e com doutorado $28,70 \%$. A maioria dos respondentes é técnico-administrativo em educação ensino superior (E) com 33,30\% e técnico administrativo em educação ensino médio (D) com 27,80\%, seguidos de professor adjunto com 24,30\%. Em relação à jornada de trabalho, a maioria trabalha 40 horas semanais ou 40 horas semanais com dedicação exclusiva (docentes), com 60,30\% e 38,60\% respectivamente.

Quanto ao tempo de serviço na universidade, destacam-se as alternativas de Até 5 anos $(34,80 \%)$ e Acima de 5 anos $(21,30 \%)$. Considerando a variável tempo total no serviço público, os percentuais mais elevados foram as alternativas Acima de 5 anos (43,50\%) e Até 5 anos $(27,40 \%)$. Para a última variável, encontrou-se que a maioria dos respondentes pesquisados não ocupa cargo de chefia $(78,10 \%)$, ao passo que $21,90 \%$ ocupam algum cargo de gestão na instituição.

\subsection{FATORES DE QUALIDADE DE VIDA NO TRABALHO}

A busca por fatores relacionados com a QVT foi realizada por meio da análise fatorial exploratória. Seguindo a indicação de livros estatísticos de análise multivariada, o primeiro passo da realização da análise fatorial consistiu na realização de cálculos referentes à adequação da utilização da análise fatorial para os dados coletados. Nesse intuito, foram realizados os testes de Esfericidade de Bartlett e KMO (Kaiser-Meyer-Olkin), que são testes estatísticos que permitem identificar a qualidade das correlações entre as variáveis, indicando

REAd | Porto Alegre - Vol. 23 - No Especial - Dezembro 2017 - p. 317-344 
se o pesquisador deve prosseguir com a análise fatorial (PESTANA; GAGEIRO, 2008). Os resultados para esses testes foram os seguintes: 0,919 para o KMO; e um sig de 0,000 para o teste de Esfericidade de Bartlett, indicando, ambos os testes, a fatorabilidade dos dados e, assim, a aplicação da análise fatorial.

Como segundo passo da realização da fatorial exploratória, efetuou-se a identificação das comunalidades apresentadas em cada uma das questões constituintes do instrumento de pesquisa. Segundo o entendimento de Hair et al. (2009), as variáveis que apresentam valores menores que 0,5 para esta medida devem ser retiradas do instrumento. Por esse motivo, foram retiradas as seguintes questões:

- "A distribuição das tarefas na universidade é justa";

- "A prática do reconhecimento contribui para a minha realização profissional”;

- "As oportunidades de crescimento profissional são iguais para todos na universidade";

- "É comum, na universidade, a não conclusão de trabalhos iniciados";

- "É fácil o acesso à chefia imediata";

- "Na universidade, tenho liberdade para dizer o que penso sobre o trabalho".

As demais variáveis apresentaram comunalidades maiores que 0,5. Com base nessas variáveis foi dada sequência na busca por fatores que afetam a QVT.

Para a rotação dos fatores, utilizou-se o modo Varimax e ,como critério de especificação do número de fatores, adotou-se como medida de estimação o Eigenvalue, cujos fatores deveriam apresentar um autovalor superior a um. Com essas decisões para a rotação da fatorial, obteve-se nove fatores que explicam $65,68 \%$ do total da variância dos dados. Na Tabela 2 são exibidos os nove fatores resultantes, bem como as variáveis que os compõem e as cargas fatoriais das mesmas. Noa referido abela são também expostos os valores do Alpha de Cronbach para cada um dos fatores.

Na Tabela 2 pode-se perceber que o Fator 1, denominado Espaço Físico, é composto por 7 variáveis que remetem às condições físicas do ambiente de trabalho e aos instrumentos e materiais nele disponíveis para a execução das atividades. Quanto a estes aspectos, Walton (1975) já evidencia em seus estudos a importância de um ambiente seguro, saudável e com salubridade para a QVT. Villarouco e Andreto (2008) afirmam que o espaço de trabalho age como catalisador de comportamentos que estão na mente do trabalhador, induzindo determinada ação, ou inibindo-a, e cita diversas variáveis associadas com o bem estar dos

REAd | Porto Alegre - Vol. 23 - No Especial - Dezembro 2017 - p. 317-344 
trabalhadores, como ruído, iluminação, temperatura, umidade e pureza do ar, ferramentas adequadas, tipo de vestimenta, etc. Isso vai ao encontro do trabalho de Bauman (1999), que afirma que em lugares de trabalho adequados o trabalhador se sente mais atraído pelo posto de trabalho, por sua atividade e pelos resultados positivos das tarefas.

Tabela 2 - Composição dos fatores resultantes da análise fatorial

(continua)

\begin{tabular}{lc}
\hline \multicolumn{1}{c}{ Descrição dos fatores } & Carga Fatorial \\
\hline OATOR 1 - ESPAÇO FÍSICO - Cronbach's Alpha (0,860) & 0,819 \\
\hline O posto de trabalho é adequado para realização das tarefas. & 0,811 \\
\hline O espaço físico para executar o meu trabalho é satisfatório. & 0,756 \\
\hline O nível de iluminação é suficiente para executar as atividades. & 0,728 \\
\hline A temperatura ambiente é confortável. & 0,693 \\
\hline Os instrumentos de trabalho são suficientes para realizar as tarefas. & 0,546 \\
\hline O material de consumo é suficiente. & 0,507 \\
\hline
\end{tabular}

FATOR 2 - OPORTUNIDADES DE CRESCIMENTO PROFISSIONAL - Cronbach's AIpha $(0,875)$

$\begin{array}{ll}\text { A universidade oferece oportunidade de crescimento profissional. } & 0,765\end{array}$

O desenvolvimento pessoal é uma possibilidade real na universidade. $\quad 0,747$

$\begin{array}{ll}\text { Há incentivos para o crescimento na carreira. } & 0,710\end{array}$

$\begin{array}{ll}\text { O comportamento gerencial é caracterizado pelo diálogo. } & 0,573\end{array}$

Sinto-me reconhecido pela Instituição onde trabalho. $\quad 0,535$

FATOR 3 - SATISFAÇÃO NO TRABALHO - Cronbach's Alpha $(0,882)$

Nessa universidade, as atividades que realizo são fontes de prazer. $\quad 0,756$

$\begin{array}{ll}\text { O tempo de trabalho que passo na universidade me faz feliz. } & 0,735\end{array}$

$\begin{array}{ll}\text { Sinto que o meu trabalho nessa universidade me faz bem. } & 0,710\end{array}$

$\begin{array}{lc}\text { Gosto da instituição onde trabalho. } & 0,676\end{array}$

FATOR 4 - RELACIONAMENTO COM COLEGAS - Cronbach's Alpha (0,799)

\begin{tabular}{ll}
\hline A convivência no ambiente de trabalho na universidade é harmoniosa. & 0,683 \\
\hline Há confiança entre os colegas. & 0,680 \\
\hline Minhas relações de trabalho com os colegas são harmoniosas. & 0,576 \\
\hline Meus colegas de trabalho demonstram disposição em me ajudar. & 0,487 \\
\hline
\end{tabular}

FATOR 5 - RECONHECIMENTO PELO TRABALHO REALIZADO - Cronbach's Alpha (0,860)

\begin{tabular}{ll}
\hline O reconhecimento do trabalho individual é uma prática efetiva nessa universidade. & 0,622 \\
\hline Nessa universidade, o resultado obtido com meu trabalho é reconhecido. & 0,567 \\
\hline O reconhecimento do trabalho coletivo é uma prática efetiva nessa universidade. & 0,566 \\
\hline Nessa universidade, minha dedicação ao trabalho é reconhecida. & 0,566 \\
\hline
\end{tabular}

FATOR 6 - RELACIONAMENTO COM A CHEFIA - Cronbach's Alpha (0,835)

\begin{tabular}{ll}
\hline Minhas relações de trabalho com a chefia são cooperativas. & 0,800 \\
\hline Minha chefia imediata tem interesse em me ajudar. & 0,785 \\
\hline Nessa universidade, recebo incentivos de minha chefia. & 0,561
\end{tabular}

REAd | Porto Alegre - Vol. 23 - No Especial - Dezembro 2017 - p. 317-344 
Tabela 2 - Composição dos fatores resultantes da análise fatorial

(conclusão)

Descrição dos fatores

Carga Fatorial

\begin{tabular}{lc}
\multicolumn{1}{c}{ Descrição dos fatores } & Carga Fatorial \\
\hline \multicolumn{2}{c}{ FATOR 7 - EXECUÇÃO DE ATIVIDADES - Cronbach's Alpha (0,796) } \\
\hline Posso executar meu trabalho sem sobrecarga de tarefas. & 0,822 \\
\hline Posso realizar meu trabalho sem pressão. & 0,785 \\
\hline Nessa universidade, disponho de tempo para executar o meu trabalho com zelo. & 0,740 \\
\hline \multicolumn{2}{c}{ FATOR 8 - AVALIAÇÃO DE DESEMPENHO E RESULTADOS - Cronbach's Alpha (0,682) } \\
\hline Nessa universidade, existe forte cobrança por resultados. & 0,767 \\
\hline Existe fiscalização do desempenho. & 0,698 \\
\hline As normas para realização das tarefas são rígidas. & 0,685 \\
\hline Há cobrança de prazos para o cumprimento das tarefas. & 0,654 \\
\hline
\end{tabular}

FATOR 9 - LIBERDADE NO AMBIENTE DE TRABALHO - Cronbach's Alpha $(0,688)$

\begin{tabular}{ll}
\hline Tenho liberdade na execução das tarefas. & 0,756 \\
\hline Tenho a possibilidade de ser criativo no meu trabalho. & 0,685 \\
\hline Nessa universidade, tenho livre acesso às chefias superiores. & 0,491 \\
\hline
\end{tabular}

Fonte: Elaborado pelos autores com base no resultado da análise multivariada.

O Fator 2 - Oportunidades de Crescimento Profissional - apresenta 5 variáveis referentes às possibilidades de desenvolvimento pessoal e crescimento na carreira. Lippitt (1978) dá suporte a essa questão do crescimento profissional ao inserir na sua definição de QVT a oportunidade de o indivíduo satisfazer suas necessidades pessoais, incluindo o desenvolvimento pessoal e o crescimento profissional. Para Westley (1979), que defende a necessidade de humanização nas atividades laborais, elementos psicológicos influenciam na QVT, dentre os quais ele aborda a realização e o desenvolvimento pessoal e profissional.

O Fator 3, denominado Satisfação no Trabalho, é formado por 4 variáveis que avaliam o quão bem o indivíduo se sente e está feliz no lugar em que trabalha. Para justificar esse fator pode-se tomar como base a definição de satisfação no trabalho dada por Locke (1976). Para ele, satisfação no trabalho é um estado de prazer emocional resultante da avaliação que um profissional faz sobre até que ponto seu trabalho apresenta a capacidade de facilitar ou permitir o atendimento de seus objetivos e valores.

A denominação do Fator 4 - Relacionamento com Colegas - se deve a ser composto por 4 variáveis que avaliam a relação dos servidores com os seus colegas de trabalho. Nesse sentido, Bolles (1981, p. 85) indica como um dos fatores de satisfação e qualidade no ambiente laboral "aqueles além de nós no trabalho", se referindo às pessoas que desempenham as mesmas tarefas (os colegas) e demais pessoas com que o trabalhador se envolve na execução do trabalho. Assim como neste artigo, Silva e Ferreira (2013), ao estudar

REAd | Porto Alegre - Vol. 23 - No Especial - Dezembro 2017 - p. 317-344 
indicadores de qualidade de vida, denominaram um dos fatores de seu trabalho de "relacionamento interpessoal com os colegas de trabalho", por conter afirmativas associadas à qualidade das relações entre os empregados no ambiente de trabalho.

O Fator 5 - Reconhecimento pelo Trabalho Realizado - foi assim denominado por ser composto por 4 variáveis que avaliam quanto a pessoa é reconhecida pelo esforço, dedicação e pelas atividades executadas. O reconhecimento foi inserido em teorias precursoras de motivação e de necessidades do ser humano, como por exemplo, a teoria dos fatores higiênicos de Herzberg e na pirâmide de Maslow, quanto esses estudiosos citaram a necessidade de estima dos indivíduos. Robbins (2006) considera o reconhecimento um agente motivador no trabalho. Assim como Sievers (1997), para quem o fato do trabalho ser reconhecido reforça o sentimento de inserção e integração social do indivíduo e aumenta seu grau de motivação com o trabalho.

Em relação ao Fator 6 - Relacionamento com a Chefia -, pode-se verificar na Tabela 2 que ele é composto por 3 variáveis que indicam como é a relação dos servidores com suas chefias. Este fator é também identificado no modelo de aferição da QVT de Fernandes (1996) com o nome de "Relação Chefia - Funcionário", e foi utilizado pelo referido autor para identificar a satisfação na relação entre superior e subordinado. $\mathrm{O}$ relacionamento de um indivíduo com sua chefia é um fator inerente à QVT, pois indica o nível de apoio sócio emocional, de orientação técnica, do uso adequado da autoridade, do tratamento perante erros etc. (FERNANDES, 1996). Esses aspectos interferem no dia-a-dia do indivíduo sendo que um bom relacionamento com a chefia estimula a QVT (OLIVEIRA, 2008).

Quanto ao Fator 7 nomeado Execução de Atividades, pode-se verificar que é composto por três variáveis que avaliam a quantidade e tempo que o servidor possui para realizar suas atividades. A relação desses aspectos com a QVT é avaliada no modelo de Walton (1973) em dois constructos, o que justifica sua importância. Primeiramente, Walton (1973) analisa a quantidade de trabalho a ser realizada em um turno de trabalho, como uma questão do fator "condição de trabalho" do seu modelo. Já o tempo para a execução das atividades o referido autor avalia no constructo "uso e desenvolvimento de capacidades" do seu modelo de avaliação da QVT.

O Fator 8, denominado Avaliação de Desempenho e Resultados, é constituído por 4 variáveis que se referem ao grau de cobrança e fiscalização por resultados no trabalho dos servidores. Como mencionam El-Aouar e Souza (2003), os estudos de QVT surgem como 
uma proposta sistematizada para conciliar o nível de satisfação do trabalhador e os interesses de patrões quanto aos níveis de desempenho desejados. Estabelecer um nível mínimo de qualidade de vida ao colaborador é uma necessidade para as organizações hoje em dia, e deve conciliar a adequada política de verificação de desempenho desse colaborador. O modelo de Werther e Davis (1983), por exemplo, identifica as tarefas concernentes a determinado cargo para que seja estabelecido o estudo da metodologia adequada à sua realização e à aferição do desempenho desejado. Eles explicam que o objetivo é tanto aumentar o desempenho quanto eliminar do cargo condições que causem insatisfação ao seu ocupante.

Por fim, o Fator 9, Liberdade no Ambiente de Trabalho, é composto por 3 variáveis que se referem à autonomia do servidor para a execução de suas atividades. Esse fator foi estudado no modelo de Hackman e Oldham (1974), que estudaram os estados psicológicos dos profissionais e como eles são percebidos na execução das atividades. Eles consideraram a autonomia uma dimensão a ser analisada durante a execução das tarefas por um indivíduo, e a definem como o grau em que a tarefa fornece aos indivíduos liberdade para planejar e executar suas atividades. Moreira (2012) explica que determinadas dimensões do trabalho, quando adequadamente fornecidas ao trabalhador, geram satisfação e motivação a ele. Uma delas seria a liberdade/autonomia do modelo de Hackman e Oldham (1974).

Os apontamentos teóricos, expostos nos parágrafos anteriores, justificam a nomenclatura dada aos fatores obtidos e remetem à importância de cada um deles na avaliação da QVT. A seguir, descrever-se-ão os resultados obtidos pela análise de regressão realizada neste trabalho e será possível identificar quais desses fatores explicam a QVT na percepção dos indivíduos pesquisados.

Com o intuito de demonstrar um panorama dos aspectos que podem estar positivamente ou negativamente relacionados à QVT, elaborou-se a Tabela 3, na qual estão expostas a média e o desvio padrão dos fatores resultantes da análise fatorial exploratória, levando-se em consideração as respostas dos servidores.

Tabela 3 - Estatística descritiva dos fatores

\begin{tabular}{lcc}
\hline & Média & Desvio Padrão \\
\hline Espaço físico & 3,44 & 1,03 \\
Oportunidades de crescimento profissional & 3,27 & 1,06 \\
Satisfação no trabalho & 3,88 & 0,97 \\
Relacionamento com colegas & 3,78 & 0,85 \\
Reconhecimento pelo trabalho realizado & 2,95 & 1,00
\end{tabular}

REAd | Porto Alegre - Vol. 23 - No Especial - Dezembro 2017 - p. 317-344 
Tabela 3 - Estatística descritiva dos fatores

\begin{tabular}{lcc} 
& & (conclusão) \\
\hline Relacionamento com a chefia & Média & Desvio Padrão \\
Dimensionamento para execução de atividades & 3,82 & 0,99 \\
Avaliação de desempenho e resultados & 3,66 & 1,01 \\
Liberdade no ambiente de trabalho & 3,03 & 0,85 \\
\hline
\end{tabular}

Fonte: Elaborado pelos autores com base no resultado da estatística descritiva.

Analisando a Tabela 3, pode-se observar que apenas o fator Reconhecimento pelo trabalho realizado apresentou um valor abaixo e próximo de 3 (valor 2,95), indicando relativa imparcialidade dos respondentes quanto a esse fator. Destaca-se, também, que todos os outros fatores apresentaram valor acima de 3. Dentre estes, ressalta-se a Satisfação no trabalho (média 3,88), o Relacionamento com a chefia"'(média 3,82), e a Liberdade no ambiente de trabalho (média 3,81), que apresentaram as maiores médias.

\subsection{FATORES INFLUENCIADORES DA SATISFAÇÃO COM A QVT}

Nesta parte deste artigo foram investigados os fatores que predizem a satisfação com a QVT dos servidores. A média da satisfação obtida foi 6,39, em uma escala do tipo Likert de zero a dez pontos, sendo que quanto mais perto da nota 10 o respondente assinalasse, mais satisfeito ele se considerava. Assim, pode-se auferir que, em geral, os servidores estão satisfeitos com a QVT.

Para investigar a influência dos fatores encontrados com a análise fatorial exploratória, realizou-se uma regressão linear múltipla. Para a estimação do modelo de regressão foi utilizado o método Stepwise e alocou-se como variável dependente a medida de satisfação/insatisfação dos servidores investigados, e como variáveis independentes os fatores identificados e explicados no item anterior deste artigo.

A Tabela 4 exibe os valores dos coeficientes das variáveis independentes do modelo resultante, bem como o valor do teste $\mathrm{T}$, do teste $\mathrm{F}$ e do $\mathrm{R}^{2}$ do modelo.

Observa-se pela análise da Tabela 4 que o Teste $\mathrm{F}$ foi significativo para o modelo resultante da Regressão Múltipla (sig $=0,003$ ) indicando que, pelo menos, uma das variáveis independentes é diferente de zero e exerce influência sobre a variável dependente. Este fato é corroborado pelo Teste $t$, pois como pode ser visualizado na Tabela 4 , todos os fatores do

REAd | Porto Alegre - Vol. 23 - No Especial - Dezembro 2017 - p. 317-344 
modelo apresentam valores de significância menores que 0,05 , o que indica que eles são estatisticamente diferentes de zero.

Tabela 4 - Resultados da Regressão Múltipla

\begin{tabular}{|c|c|c|c|c|c|c|}
\hline \multirow[b]{2}{*}{ Fatores } & \multirow{2}{*}{$\begin{array}{c}\begin{array}{c}\text { Coeficiente } \\
\text { Padronizado }\end{array} \\
\text { Beta } \\
\end{array}$} & \multirow[b]{2}{*}{$\mathbf{t}$} & \multirow[b]{2}{*}{ Sig. } & \multirow{2}{*}{$\begin{array}{c}\mathbf{R} \\
\underset{\left(\mathbf{R}^{2}\right)}{\text { quadrado }}\end{array}$} & \multicolumn{2}{|c|}{ Teste F } \\
\hline & & & & & Valor & Sig. \\
\hline Constant & $-2,815$ & $-6,618$ & 0,000 & \multirow{5}{*}{0,546} & \multirow{5}{*}{8,679} & \multirow{5}{*}{0,003} \\
\hline Satisfação no trabalho & 0,397 & 9,647 & 0,000 & & & \\
\hline Espaço físico e ferramentas de trabalho & 0,200 & 5,652 & 0,000 & & & \\
\hline Oportunidades de crescimento profissional & 0,230 & 5,634 & 0,000 & & & \\
\hline Relacionamento com os colegas & 0,112 & 2,946 & 0,003 & & & \\
\hline
\end{tabular}

Fonte: Elaborado pelos autores com base no resultado da análise multivariada.

Nota: Variável Dependente - Satisfação dos servidores com a qualidade de vida

Em relação às medidas de verificação da validade do modelo, utilizadas nesse trabalho, pode-se verificar que o modelo atende a todas as medidas avaliadas. Observou-se, primeiramente, que o modelo não apresenta problemas de auto correlação, uma vez que o valor do teste de Durbin Watson apresentou valor de 1,927, atendendo ao critério de Gujarati e Porter (2009). O modelo de regressão também não apresenta problemas de multicolinearidade entre as variáveis independentes, dado que as medidas TOL e VIF apresentam valores próximos de 1,0, o que atende os critérios de não multicolinearidade dos fatores (HAIR et al.,2009). Verificou-se, também, que o modelo atende aos pressupostos de normalidade, pois o Teste K-S não apresentou um valor significativo a 5\%, (sig > 0,05). Nesse caso, aceita-se a hipótese nula de normalidade dos resíduos do modelo. Por fim, verificou-se por meio do teste Pesaran-Pesarán, que o modelo de regressão estimado não possui problemas de heterocedaticidade dos dados, ou seja, a variância dos resíduos mantémse constante em todo o espectro das variáveis independentes utilizadas no modelo (GUJARATI; PORTER, 2009).

Por meio da análise da Tabela 4, pode-se verificar ainda que a medida qualidade de ajustamento do modelo de regressão formado, determinada pelo " $\mathrm{R}^{2}$ ", é de 54,6\%. Este percentual indica o quanto da variável dependente é explicada pelas variáveis independentes, ou seja, é uma medida de ajuste da reta de regressão (HAIR et al., 2009). Dessa forma, podese dizer que nesse trabalho, 54,6\% da variabilidade de Y (QVT) pode ser explicada pelos seguintes fatores: Satisfação no trabalho (Fator 3), Espaço Físico (Fator 1), Oportunidade de crescimento profissional (Fator 2) e Relacionamento com os colegas (Fator 4). Tendo como 
base os coeficientes Beta de cada um dos fatores independentes, que expressam a magnitude e a direção da relação desses fatores sobre a variável dependente $\mathrm{Y}$, o modelo de regressão resultante é expresso pela Equação 1.

\section{Equação 1: \\ $\mathrm{Y}=-\mathbf{2 , 8 1 5}+\mathbf{0 , 3 9 7} *($ Fator 3$)+\mathbf{0 , 2 0 0} *($ Fator 1$)+\mathbf{0 , 2 3 0} *($ Fator 2$)+\mathbf{0 , 1 1 2} *($ Fator 4$)$}

A análise do modelo de regressão expresso pela Equação 1 revela que o fator que possui o maior peso para a explicação de "Y" é Satisfação no Trabalho. As estatísticas descritivas, apresentadas anteriormente na Tabela 3, mostram que este foi o fator que obteve a maior média entre os respondentes (média $=3,88$ ), o que demonstra a importância da satisfação no trabalho para o objeto estudado nesse artigo. Este resultado vai ao encontro de outros estudos, como os de Babu e Ramesh (2013) e de Taylor (1977), que verificaram uma relação positiva entre a satisfação no trabalho e a QVT. Outros pesquisadores afirmam que a QVT não está somente relacionada com bem-estar e sentimentos dos empregados com o seu trabalho, mas sim com a satisfação deles com o seu trabalho (SIRGY et al., 2001).

O resultado exposto na Equação 1 também revela que o Espaço Físico exerce uma influência sobre a QVT para os indivíduos pesquisados nesse artigo. Isso pode ser justificado pelo entendimento de Fernandes (1996), que explica que a QVT é uma gestão dinâmica e contingencial de fatores físicos, tecnológicos e sócio psicológicos que afetam a cultura e renovam o clima organizacional, refletindo-se no bem-estar do trabalhador e na produtividade das empresas. Como exposto anteriormente, Walton (1975) também salienta a importância de um ambiente físico seguro e saudável, que apresente boas condições de segurança e de saúde em relação aos riscos de injúria ou de doenças, como influente na QVT. Similarmente, Nadler e Lawler (1983) também defendem a importância do ambiente físico para o alcance da QVT,= e, consequentemente, para maior produtividade dos indivíduos.

Outro fator que influencia a satisfação com a QVT, de acordo com os resultados dessa pesquisa, é a Oportunidade de Crescimento Profissional (Fator 2). Como pode ser visto na Equação 1, o aumento desse fator em uma unidade, eleva a satisfação com a QVT em 0,230 unidade, caso os outros fatores sejam mantidos constantes. Este resultado corrobora os pressupostos de Fernandes (1996). Este último menciona que para analisar a QVT é preciso

REAd | Porto Alegre - Vol. 23 - No Especial - Dezembro 2017 - p. 317-344 
considerar, dentre outros fatores, as oportunidades o crescimento pessoal e profissional do indivíduo.

Por fim, pode-se verificar na Equação 1 que o fator Relacionamento com os Colegas é outro fator que explica a satisfação com a QVT. De acordo com Walton (1973), respeito entre os colegas de trabalho caracteriza-se como uma dimensão da qualidade de vida e bemestar no trabalho. O bom relacionamento com os colegas de trabalho para a QVT foi também identificado no trabalho de Argentero, Miglioretti e Angilletta (2007), que realizaram estudos no sentido de analisar os indicadores de QVT em uma empresa italiana de trabalhadores da saúde.

\section{CONSIDERAÇÕES FINAIS}

Levando em consideração a cobrança da sociedade pela valorização do ser humano, muitas organizações passaram a desenvolver um novo modelo de gestão, apostando no equilíbrio entre a saúde física, emocional, social, intelectual, ocupacional e espiritual de seus colaboradores. Buscam, com isso, implementar condições que agreguem capacidade criativa, potencial e motivacional do colaborador, visando a QVT dos mesmos. Assim, estudos sobre QVT têm sido elaborados em diversos campos de estudo para avaliar fatores e variáveis sobre o assunto e corroborar para a consolidação do tema. Nessa perspectiva, este artigo tem como objetivo analisar quais os fatores direcionadores da QVT, com base na percepção de servidores de uma organização pública.

Para alcançar o objetivo foi elaborada uma pesquisa empírica estruturada e sustentada por teoria condizente ao objeto de estudo. Realizou-se, primeiramente, uma análise fatorial exploratória e obteve-se nove fatores explicativos da QVT a partir dos resultados desse procedimento. Com base nesses fatores, realizou-se uma análise de regressão tendo como variável dependente a satisfação dos servidores com a QVT. Esta variável apresentou uma média de 6,5 em uma escala de 0 a 10, o que indica que os servidores da universidade pesquisada consideram-se satisfeitos quanto a QVT. Verificou-se que quatro fatores predizem a variável dependente do modelo de regressão, são elas: (1) Satisfação no trabalho, (2) Espaço físico, (3) Oportunidade de crescimento profissional e (4) Relacionamento com os colegas. Essas variáveis apresentam em conjunto um grau de explicação $\left(\mathrm{R}^{2}\right)$ de 54,6\%.

REAd | Porto Alegre - Vol. 23 - No Especial - Dezembro 2017 - p. 317-344 
Como conclusões obtidas nesse trabalho, pode-se destacar que os respondentes desse estudo encontram-se satisfeitos quanto a QVT, no entanto, somente com a explicação de quatro fatores. A QVT, para os participantes da pesquisa, se mostra como sinônimo de um ambiente agradável de trabalho, tanto em relação à estrutura física quanto à harmonia na relação com os colegas, com perspectivas de crescimento profissional e satisfação em relação ao trabalho.

Outro ponto a ser ressaltado é que, nesse estudo, a QVT não é explicada por alguns fatores que podem ser observados do ponto de vista da organização e suas práticas, sejam eles: "reconhecimento pelo trabalho realizado" e "avaliação de desempenho e resultados". Fatores estes que apresentam as menores médias. Em relação a esses pontos é que a IES tem quedirecionar melhorias, pois como Ferreira (2011) salienta, a QVT pode também ser utilizada como meio para o enfrentamento de diversos problemas existentes nos ambientes corporativos. Dessa forma, ações de reconhecimento do trabalho e medidas ou ferramentas que auxiliem os colaboradores na verificação de desempenho podem evitar problemas futuros como baixa motivação no trabalho e stress e conduzir a melhor eficiência no trabalho que realizam.

Em geral, os resultados encontrados nesse estudo revelam aspectos a serem considerados para a compreensão do ambiente de trabalho de indivíduos no serviço público. Repensar e redefinir o papel e atividades dos gestores públicos com base nos elementos aqui encontrados é relevante, pois possibilita o entendimento das dúvidas, desafios e expectativas daqueles que ocupam os diferentes cargos de uma organização e aumenta a participação de dirigentes e gestores em ações dessa natureza. O impacto desses fatores não se limita somente a uma melhora na qualidade de vida dos trabalhadores, mas também na sua produtividade (SIRGY et al., 2001), no comprometimento no trabalho (CHINOMONA et al., 2010), na saúde do trabalhador (LACAZ, 2003) e na redução do absenteísmo (DANNA; GRIFFIN, 1999). De maneira geral, esse estudo expande e fortifica ainda mais os horizontes de compreensão de fatores de qualidade de vida, relevantes para a gestão de pessoas das organizações.

Em relação à pesquisa empírica realizada nesse artigo, considera-se temeroso inferir que o método e, principalmente os resultados descritos, se apliquem às organizações do setor público em geral. O que dá suporte ao valor científico do estudo aqui relatado são as mudanças e reflexões organizacionais sobre QVT que podem ser realizadas. Coloca-se assim 
como limitação desse estudo a restritiva generalidade dos resultados encontrados. Outra questão a ser considerada é o aprofundamento dessa pesquisa. Restringiu-se a coleta e análise dos dados desse trabalho a uma abordagem quantitativa, visando determinada amplitude de opiniões para possibilitar a generalização para a população estudada. No entanto, não se desqualifica a importância de estudos futuros, que adotem pesquisas qualitativas, focadas em uma determinada categoria, investiguem o processo de implementação de Programas de QVT, ou que investiguem comparativamente as percepções de dirigentes e colaboradores. Por fim, sugere-se também a realização de pesquisas futuras que explorem a relação entre a QVT e produtividade dos indivíduos.

\section{REFERÊNCIAS}

AMALBERTI, R.; MONTMOLLIN, M; THEUREAU, J. Modèles en analyse du travail. Liège, France: Mardaga, 1991.

ARGENTERO, P.; MIGLIORETTI, M.; ANGILLETTA, J. Quality of work life in a cohort of Italian health workers. Giornale Italiano di Medicina del Lavoro ed Ergonomia, v. 29, n. 1, p. 50-54, 2007.

BABU, R. H.; RAMESH, M. Relationship between job satisfaction and quality of work life of employees in service sector. Perspectives of Innovations, Economics \& Business, v.13, n.2, p. 58- 67, 2013.

BAUMAN, M. Modernidade e ambivalência. Rio de Janeiro: Jorge Zahar, 1999.

BISWAS, S. Relationship between psychological climate and turnover intentions and its impact on organisational effectiveness: a study in Indian organisations. IIMB Management Review, v. 22, p. 102-110, 2010.

BOLLES, R.N. The three boxes of life and how to get out of them: an introduction to lifework planning. Berkeley: Ten Speed Press, 1981.

BOM SUCESSO, E. P. Trabalho e qualidade de vida. 1.ed. Rio de Janeiro: Dunya, 1998.

CAVEDON, N. R. A qualidade de vida no trabalho na área da Segurança Pública: uma perspectiva diacrônica das percepções olfativas e suas implicações na saúde dos servidores. Organizações \& Sociedade, v.21, n.68, p. 875-892, 2014.

REAd | Porto Alegre - Vol. 23 - No Especial - Dezembro 2017 - p. 317-344 
CHINOMONA, R.; CHENG, J. Distribution channel relational cohesion exchange model: a small-to-medium enterprise manufacturer's perspective. Journal of Small Business Management, v.51, n.2, p. 256-275, 2013.

CHINOMONA, R., LIN, J., WANG, M.; CHENG, J. Soft power and desirable relationship outcomes in Zimbabwe distribution channels. African Journal of Business, v. 11, n. 2, p. 20$55,2010$.

CLARO, J. A. C. S.; PROFETA, R. A. Programas de benefícios sociais para docentes no ensino superior brasileiro como forma de reter talentos: um estudo exploratório. Avaliação. v. 20, n. 1, p. 189-223, 2015.

DANNA, K.; GRIFFIN, R.W. Health and well-being in the workplace: A review and synthesis of the literature. Journal of Management, v. 25, n. 3, p. 357-384, 1999. EFRATY, D.; SIRGY, M.J. The effects of quality of working life (QWL) on employee behavioral responses. Social Indicators Research, v. 22, n. 1, p. 31-47, 1990. EFRATY, D.; SIRGY, M.J.; CLAIBORNE, C.B. The effects of personal alienation on organisational identification: a quality-of-work life model. Journal of Business and Psychology, v. 6, p. 57-78, 1991.

EL-AOUAR, W. A.; SOUZA, W. J. Com músicos, com qualidade e com vida: contribuições teórico-metodológicas aos estudos em qualidade de vida no trabalho (QVT). In: Encontro da Associação Nacional de Pós-Graduação e Pesquisa em Administração, 27., 2003, Atibaia/SP. Anais ... Atibaia: ANPAD, 2003.

FERNANDES, E. C. Qualidade de Vida no Trabalho: como medir para melhorar. 2. ed., Salvador, BA: Casa da Qualidade, 1996.

FERREIRA, M. C. Qualidade de Vida no Trabalho: uma abordagem centrada no olhar dos trabalhadores. Brasília: LPA Edições, 2011.

FERREIRA, R. R.; FERREIRA, M. C.; ANTLOGA, C. S.; BERGAMASCHI, V. Concepção e implantação de um programa de qualidade de vida no trabalho no setor público: o papel estratégico dos gestores. RAUSP, v. 44, n. 2, p. 147-157, 2009.

GUEST, R. H. Quality of work life: learning from Tarrytown. Harvard Business Review, v. 57, p. $76-87,1979$.

GUJARATI, D.; PORTER, D. Basic Econometrics. 5th ed. New Yorl: McGraw-Hill, 2009. 
HACKMAN, J. R.; OLDHAM, G. R. The job diagnostic survey: an instrument for the diagnosis of jobs and the evaluation of job redesign projects. Technical report. n. 4, Department of Administrative Sciences of Yale University, 1974.

HAIR, J. F.; BLACK, W. C.; BABIN, B. J.; ANDERSON, R. E. Multivariate data analysis. Upper Saddle River: Prentice Hall, 2009.

IGBARIA, M.; PARASURAMAN, S.; BADAWY, M.K. Work experiences, job involvement, and quality of work life among information systems personnel. MIS Quarterly, v. 18, n. 2, p. 175-201, 1994.

KOYS, D. J. The effects of employee satisfaction, organisational citizenship behavior and turnover on organisational effectiveness: a unit-level, longitudinal study. Personnel Psychology, v. 54, p. 101-114, 2001.

GOLDENBERG, P., MARSIGLIA, R.M.G..; GOMES, M.H.A. (Orgs.). O clássico e o novo: tendências, objetos e abordagens em ciências sociais e saúde. Rio de Janeiro: Fiocruz, 2003. LIPPITT, G. L. Quality of work life: organization renewal in action. Training and Development Journal, v. 32, n. 1, 1978.

LOCKE, E. A. The nature and causes of job satisfaction. In: DUNNETTE, M. D. (Ed.). Handbook of industrial and organizational psychology. Chicago: Rand McNally, 1976. p. 1297-1349.

MAXIMIliAnO, A. C. A. Teoria Geral da Administração. São Paulo: Atlas, 2007. MOREIRA, A. Z. A percepção dos funcionários não docentes acerca da qualidade de vida no trabalho nas instituições de ensino superior. 2012. 98 f. Dissertação (Mestrado em Administração) - Curso de Mestrado Acadêmico em Administração do Centro de Estudos Sociais Aplicados, Universidade Estadual do Ceará, Fortaleza, 2012.

NADLER, D. A; LAWLER, E. E. Quality of work life: perspectives and directions. Organizational Dynamics, v. 11, n. 3, p. 20-30, 1983.

OLIVEIRA, R. R. Qualidade de Vida no Trabalho - QVT e Responsabilidade Social Empresarial - RSE: um estudo sobre a satisfação de QVT com funcionários voluntários em programas RSE. 2008. 136 f. Dissertação (Mestrado em Administração), Universidade Metodista de São Paulo, São Bernardo do Campo, 2008.

OLIVEIRA, R. R.; SILVA, I. B.; CASTRO, D. S. P.; LIMONGI-FRANÇA, A. C. Qualidade de Vida no Trabalho - QVT dos Professores de Ensino Técnico Federal: os fatores

REAd | Porto Alegre - Vol. 23 - No Especial - Dezembro 2017 - p. 317-344 
biopsicossociais e organizacionais de satisfação. Revista de Administração da UNIMEP, v. 11, n. 2, p. 143-173, 2013.

PESTANA, M. H.; GAGEIRO, J. N. Análise de dados para ciências sociais: a complementaridade do SPSS. 5a ed. Lisboa: Silabo, 2008.

ROBBINS, S. Comportamento Organizacional. 11 a . ed. São Paulo: Pearson Prentice Hall, 2006.

SANT'ANNA, A.S.; KILIMNIK, Z.M.; MORAES, L.F. Antecedentes, origens e evolução do movimento em torno da qualidade de vida no trabalho. In: SANT'ANNA, A.S.; KILIMNIK, Z.M. (Orgs.). Qualidade de vida no trabalho: abordagens e fundamentos. Rio de janeiro: Elsevier; Belo Horizonte/MG: Fundação Dom Cabral, 2011. p. 3-30.

SANT'ANNA, A.; MORAES, L. F. Programas de qualidade de vida no trabalho: um estudo de caso em empresa brasileira do setor de telecomunicações. In: Encontro da Associação Nacional de Pós-Graduação e Pesquisa em Administração. Anais... Foz do Iguaçu, Anpad, 1999.

SIEVERS, B. Além do sucedâneo da motivação. In: CODA, R. (Org.). Psicodinâmica da vida organizacional: motivação e liderança. São Paulo: Atlas, 1997. p. 105-115

SILVA, C. A.; FERREIRA, M. C. Dimensões e indicadores da qualidade de vida e do bemestar no trabalho. Psicologia: Teoria e Pesquisa, v. 29, n. 3, p. 331-339, 2013.

SIQUEIRA, M.; MENDES, A. Gestão de pessoas no setor público e a reprodução do discurso do setor privado. Brasília: Revista do Serviço Público, v. 60, n. 3, p. 241-250, 2009.

SIRGY, M. J.; EFRATY, D.; SIEGEL, P.; LEE, D-J. A new measure of quality of work life (QWL) based on need satisfaction and spillover theories. Social Indicators Research, v. 55, n. 3, p. 241-302, 2001.

TAYLOR, J. C. Job satisfaction and quality of working life: a reassessment. Journal of Occupational Psychology, v. 50, n. 4, p. 243-252, 1977.

TRALDI, M. T. F.; DEMO, G. Comprometimento, bem-estar e satisfação dos professores de Administração de uma Universidade Federal. Revista Eletrônica de Administração, v. 72, n. 2, p. 290-316, 2012.

VASCONCELOS, P. H.; ALVES, C. E. L.; SANTOS, S. F. M.; FRANCISCO, A. C. Qualidade de vida no Ttrabalho cocente: um estudo de caso em uma instituição de ensino superior. Revista de Administração e Inovação, v. 9, n. 2, p. 79-97, 2012.

REAd | Porto Alegre - Vol. 23 - No Especial - Dezembro 2017 - p. 317-344 
VILLAROUCO, V.; ANDRETO, L. F. M. Avaliando desempenho de espaços de trabalho sob o enfoque da ergonomia do ambiente construído. Produção, v. 18, n. 3, p. 523-539, 2008. WALTON, R. Criteria for quality life. In: DAVIS, L. A. B.; CHERNS, A. B. (Eds.). The quality of working life: problems, prospects and state of the art. New York: The Free Press, 1975. p. $91-104$

WALTON, R. Quality of work life: what is it? Sloan Management Review, v. 15, n. 1, p. 11-21, 1973.

WERTHER, W. B.; DAVIS, K. Administração de pessoal e recursos humanos. São Paulo: McGraw-Hill, 1983.

WESTLEY, W. A. Problems and solutions in the quality of working life. Human Relations, v. 32, n. 2, p. 113-123, 1979.

REAd | Porto Alegre - Vol. 23 - No Especial - Dezembro 2017 - p. 317-344 